\title{
P-0722 Screening for diabetic foot using a point-of-care nerve conduction
}

device

J. Adachi ${ }^{1}$, C. Maki ${ }^{1}$, T. Horiuchi².

${ }_{1}^{1}$ Tokyo metropolitan health and medical treatment corporation Ohkuho hospital, Endocrinology and Metabolism, Tokyo, Japan. ${ }^{2}$ Kyoujokai Clinic, Department of internal medicine, Tokyo, Japan.

\section{Background}

Diabetic foot is a serious complication of diabetes and can lead to amputation of the affected extremity, thereby decreasing patient quality of life. Diabetic neuropathy (DN) is a major cause of diabetic foot. Therefore, medical providers should appropriately evaluate neuropathy in patients with diabetes.

- Specific for sural nerve
- Measures in less than 5 minutes

Aim

We measured DN using the POCD and compared our results to those from neurological examinations and clinical variables.

\section{Methods}

Participant demographics: 42 men and 20 women (5 type 1 and 57 type 2 diabetes patients, average age $65 \pm 13$ years (mean \pm SD), BMI $25.1 \pm 4.3 \mathrm{~kg} / \mathrm{m}^{2}$, median duration of diabetes 13.5 years)

1) Patients underwent sural nerve conduction velocity (SNCV) and sural nerve amplitude potential (SNAP) tests using the POCD (DPNcheck, Neurometrix Inc., Waltham, MA). We graded the severity of DN using DPN-check communicator software.

2) We explored the association between the nerve conduction study results and clinical variables, the relationship between $\mathrm{DN}$ severity and physical examinations, and the risk factors for DN measured using the POCD.

\section{Results}

\section{Prevalence of DN and diabetic foot}

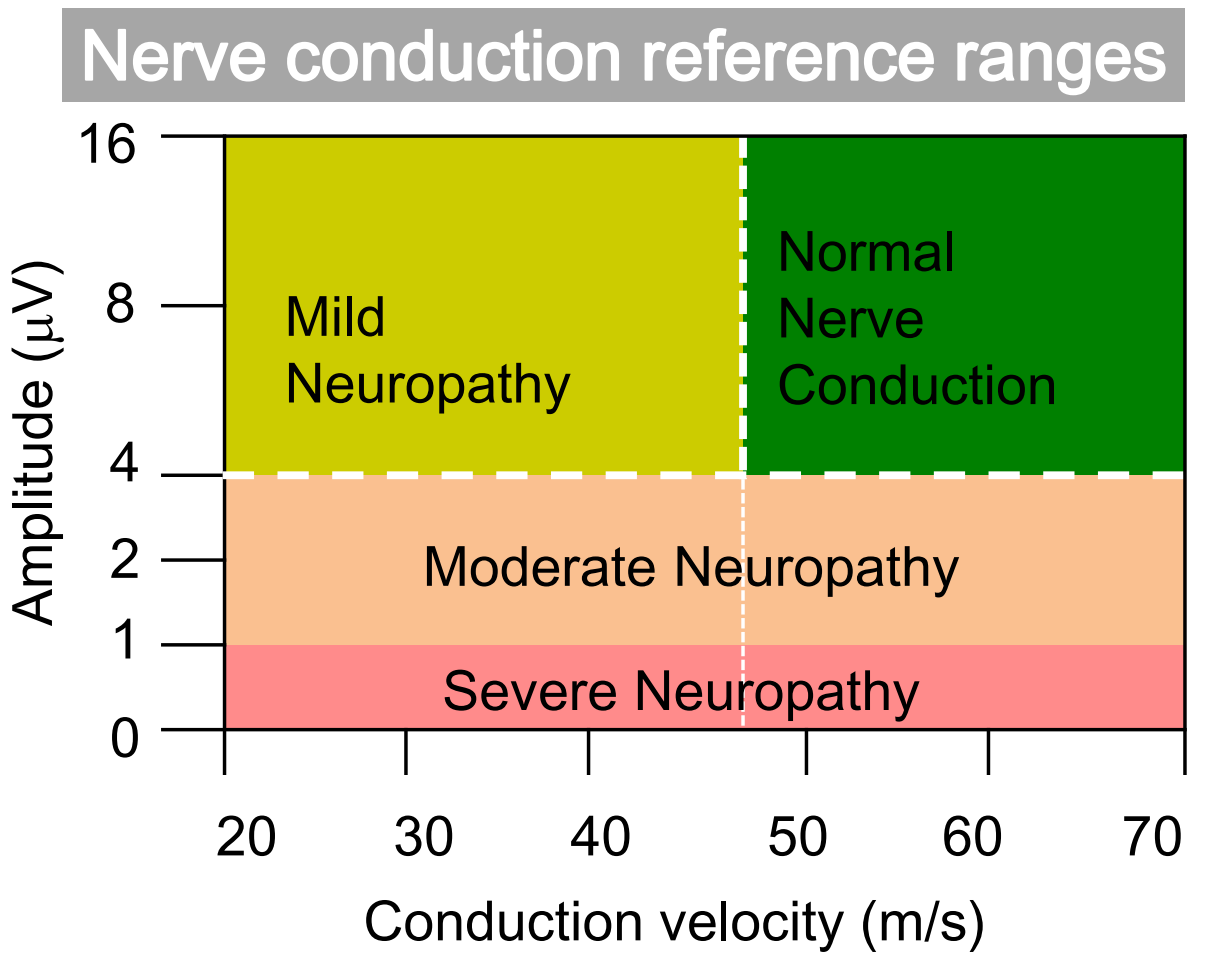

Foot ulcer: 1 patient Gangrene: 2 patients

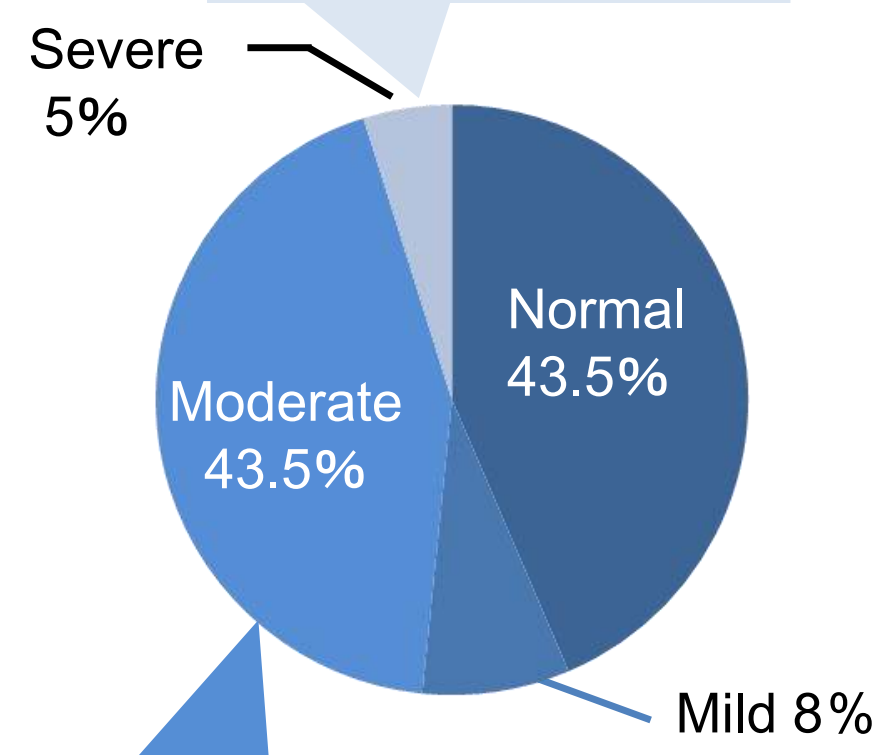

Foot ulcer : 2 patients

Amputated: 2 patients

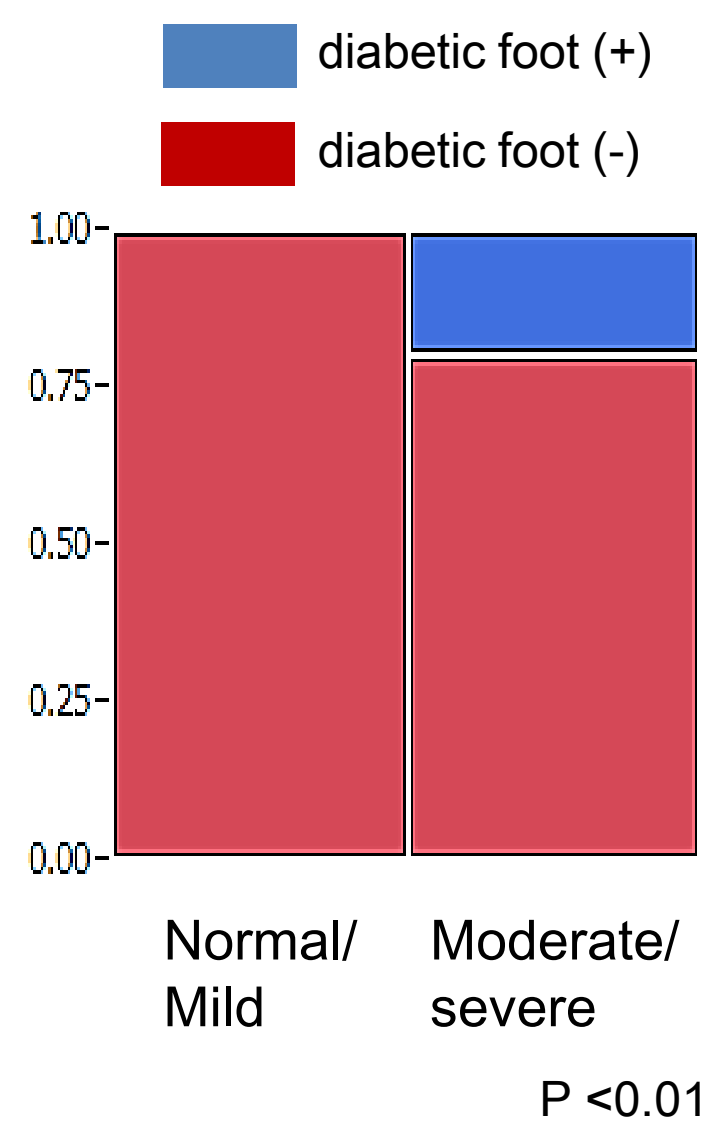

\begin{tabular}{lll}
\multicolumn{4}{c}{ Associated variables } \\
\hline SNCV \\
\hline Variable & $r$ & $P$ Value \\
\hline Age & -0.05 & 0.7 \\
Height & -0.13 & 0.3 \\
Body weight & 0.03 & 0.85 \\
HbA1c & 0.16 & 0.25 \\
$\begin{array}{l}\text { Duration of } \\
\text { diabetes }\end{array}$ & -0.29 & 0.03 \\
\hline
\end{tabular}

\begin{tabular}{lll}
\hline SNAP & & \\
\hline Variable & $r$ & $\mathrm{P}$ Value \\
\hline Age & 0.22 & 0.08 \\
Height & -0.1 & 0.41 \\
Body weight & -0.35 & $<0.01$ \\
HbA1c & -0.13 & 0.31 \\
$\begin{array}{l}\text { Duration of } \\
\text { diabetes }\end{array}$ & -0.12 & 0.37 \\
\hline
\end{tabular}

The severity of DN and physical examinations
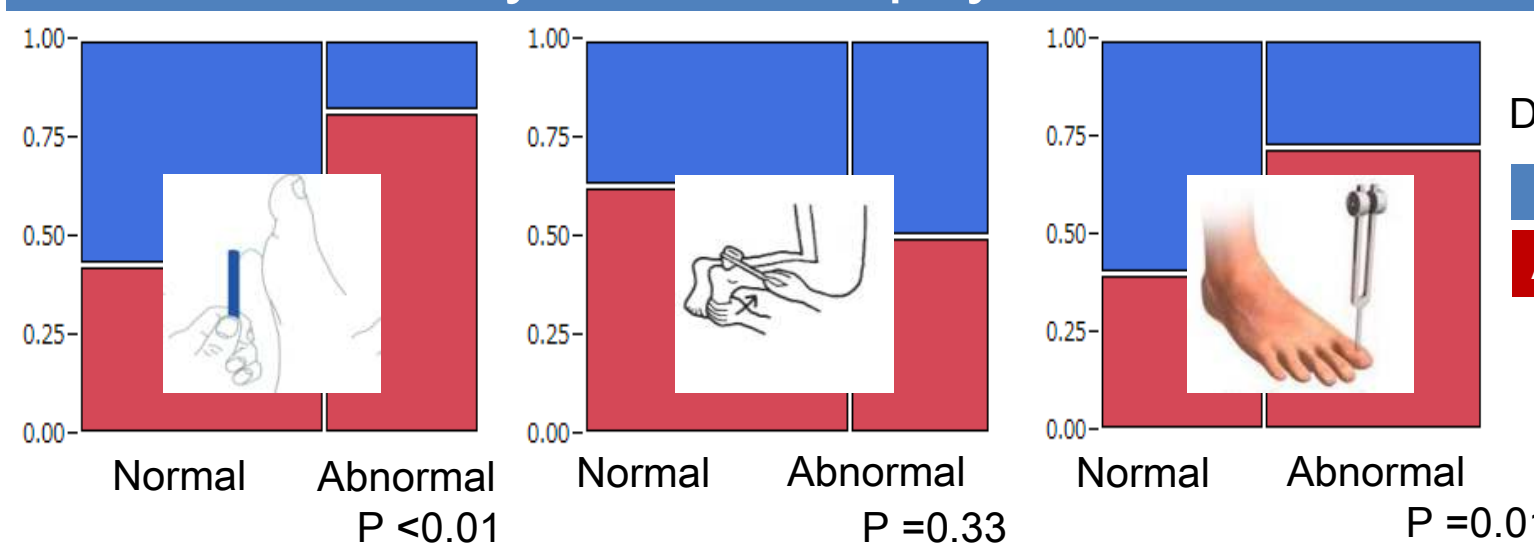

\begin{tabular}{ll|ll}
\multicolumn{4}{c}{ Risk factors for DN } \\
& Odds Ratio & $95 \% \mathrm{Cl}$ & $\mathrm{P}$ Value \\
\hline Ages & 0.97 & $0.90-1.03$ & 0.33 \\
\hline Duration of diabetes & 1.05 & $0.97-1.17$ & 0.24 \\
\hline BMI & 1.05 & $0.88-1.26$ & 0.60 \\
\hline $\mathrm{HbA1c}$ & 1.21 & $0.78-1.96$ & 0.40 \\
\hline Sex (M) & 0.71 & $0.13-3.91$ & 0.69 \\
\hline Diabetic retinopathy & 9.52 & $2.22-53.7$ & $<0.01$ \\
Smoking & 0.65 & $0.11-3.19$ & 0.59
\end{tabular}

\section{Conclusion}

- Patients who were diagnosed with moderate or severe DN may be at a higher risk of developing diabetic foot.

- Diabetic patients with retinopathy should be provided with using POCD for DN and periodical foot care. 